\title{
Effect of Nitrogen Sources on Growth and Sporulation of Alternaria alternata causing Blight Disease in Litchi
}

\author{
Ajit Kumar Dubedi Anal ${ }^{1}$, Ajit Varma ${ }^{1}$, Vinod Kumar ${ }^{2}$, \\ Shalini Rai ${ }^{3}$ and Anil Chandra ${ }^{1}$
}

${ }^{1}$ Amity Institute of Microbial Technology, Amity University, Noida Sector-125, Uttar Pradesh-201313, India

${ }^{2}$ ICAR-National Research Centre on Litchi, Mushahari, Muzaffarpur, Bihar- 842 002, India ${ }^{3}$ Department of Biotechnology, Society of Higher Education and Practical Application (SHEPA), Varanasi, Uttar Pradesh, India

*Corresponding author

\section{A B S T R A C T}

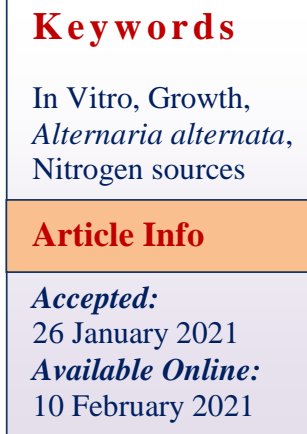

Keywords

In Vitro, Growth, Alternaria alternata, Nitrogen sources

Article Info

26 January 2021

10 February 2021
Invitro investigation was conducted to study of different nitrogen sources effect on growth and sporulation of Alternaria alternata causing blight disease in litchi. In experiment used different nitrogen sources viz, Potassium Nitrate, Sodium Nitrate, Peptone and Thiourea. The effect of nitrogen sources on growth of fungi were estimated in the term of radial myceial growth and biomass production. The Potassium Nitrate showed that most suitable source for the utilization nitrogen for growth and sporulation for Alternaria alternata.

\section{Introduction}

Litchi plants interact with biotic and abiotic factors which have direct impact on production and productivity of plant. Among different biotic factors, the fungal blight disease caused by Alternaria alternata has emerged as the most important pathogen of litchi. This occurs at various levels of development stage like leaf, panicle and fruit (Kumar et al., 2018). According to the report of Kumar and Anal (2018), the incidence of disease incidence of leaf blight was 7.1 to 82.6 $\%$ in nursery plants while percent disease severity index (PDI) was 43.3-71.2. The higher disease incidence of leaf blight was recorded in July, August and September months, while it was lower in November to January (Anal et al., 2019). The disease incidence of panicle blight in different orchards was 6.3 to $77.1 \%$ in cultivar. 'Shahi' and $17.0-58.9 \%$ in cv. 'China'. The incidence of fruit blight in cv. 'China' was ranged from 6.6 to $17.3 \%$ in $2014-16$. The incidence and 
severity of disease at different growth phases were considerably high to cause economic loss to the crop, and if a cumulative loss at different stages is considered, the pathogen $A$. alternata becomes much more important.

Alternaria alternata used diverse nutrient for their growth and development. In In vitro study, Alternaria alternata isolate was used in media containing different nitrogen sources for studies the radial growth, dry mass and sporulation. The knowledge on the influence of different nitrogen sources on growth of the pathogen as well as sporulation of the pathogen isolated from litchi plant is needed to be developed for suitable management strategies of the disease and may help in taxonomical and physiological study of the fungus. So present investigation was undertaken to evaluate the efficacy of different nitrogen source on growth and sporulation of Alternaria alternata.

\section{Materials and Methods}

\section{Effect of nitrogen sources on growth}

The nitrogen requirement of the fungus was studied using Richard's Agar and Richard's broth media. The quantity of nitrogen compounds added was determined on the basis of their molecular weight. Nitrogen sources used in study were Potassium nitrate, Sodium nitrate, Peptone and Thiourea.

All the above nitrogen sources were mixed thoroughly and the $\mathrm{pH}$ of the medium was adjusted to 7.0 by using $0.1 \mathrm{~N}$ sodium hydroxide or $0.1 \mathrm{~N}$ hydrochloric acid. The sterilized agar media and broth were poured in sterile petriplates and $50 \mathrm{ml}$ conical flask respectively. The actively growing 5 day old mycelia of $5 \mathrm{~mm}$ disc was inoculated at the centre of the petriplate. This was then incubated for 8 days at $27 \pm 1{ }^{\circ} \mathrm{C}$. The treatments were replicated thrice. The
Diameter of mycelia growth was recorded in each treatment. After 8 days of inoculation, 1 $\mathrm{ml}$ of Tween 80 was poured in Petri dishes and the conidia were scraped off gently with a spatula. Conidial count was examined by putting $0.1 \mathrm{ml}$ of suspension on a glass slide and observed under microscope in bright fields $(10 \times)$ to know degree of sporulation.

Sporulation degree: $+=0-10$ conidia/ microscopic field, $++=10-20$ conidia/ microscopic field, $+++=20-30$ conidia/ microscopic field, $++++=>30$ conidia/microscopic field.

To assess growth in liquid medium, each conical flask having $50 \mathrm{ml}$ sterilized medium was inoculated with a $5 \mathrm{~mm}$ mycelial disc taken from 5-day old culture then were incubated at $27 \pm 1{ }^{\circ} \mathrm{C}$. After 15 days of incubation, mycelia were collected on filter paper and dried in hot air oven at $60{ }^{\circ} \mathrm{C}$ for 24 h. Dry weight of mycelia was recorded.

\section{Statistical analysis}

The data were statistically analyzed by analysis of variance (ANOVA) with SAS version 9.2 software (SAS Institute, Cary, NC, USA) using a completely randomized block design. The least significant differences (LSDs) between means at 5\% level of significance $(\mathrm{p} \leq 0.05)$ and the standard error (SE) of means were computed.

\section{Results and Discussion}

The results revealed that of the four nitrogen sources tested, Potassium nitrate was found most suitable and encouraged maximum radial mycelial growth $(8.83 \mathrm{~cm}$ ) (Table 1 and Figure 1). The second best nitrogen source found was Sodium nitrate $(6.72 \mathrm{~cm})$ and this was followed by Peptone $(40.00 \mathrm{~cm})$, Thiourea was found least suitable which recorded minimum radial mycelial growth 
$(2.57 \mathrm{~cm})($ Table 1$)$. The maximum mycelial dry mass was Potassium amended medium $(2.11 \mathrm{~g})$ followed by sodium nitrate $(2.01 \mathrm{~g})$ and peptone $(1.59 \mathrm{~g})$. The minimum dry mass was in thiourea $(0.45 \mathrm{~g})$ (Table 1 and Figure 1). The fungi use nitrogen for their structural and functional processes, like wise carbon source. Nitrogen is very important element in the protein synthesis but not all the sources of nitrogen are equally good for the growth and sporulation of all fungi.

Nitrogen is an essential requirement for growth, and the ability to metabolize a wide variety of nitrogen sources enables fungi to colonize different environmental niches and survive nutrient limitations. Favoured nitrogen sources, particularly ammonium and glutamine, are used preferentially, while the expression of genes required for the use of various secondary nitrogen sources is subject to a regulatory mechanism called nitrogen metabolite repression. According to Taware et al., (2014), Potassium nitrate was found most suitable and encouraged maximum radial mycelial growth followed by peptone, sodium nitrate, ammonium nitrate and thiourea respectively but Urea was found least suitable for radial mycelial growth of the test pathogen
A. carthami causing Alternaria blight of safflower. Vibha and Sinha (2005), said that the potassium nitrate was most appropriate source of nitrogen for growth and sporulation of the various cellulolytic fungi.

According to Ramjegathesh and Ebenezar, (2012), among the different nitrogen sources used in the study, potassium nitrate amended medium was highly suitable for the growth $A$. alternata. Cochrane (1958), discussed the inferiority of ammonia salt as a source of nitrogen in some fungus. The reason behind this is urea break down into ammonia on autoclaving and ammonia in high concentration is toxic to fungi. Ammonia may be accumulated to an inhibitory level in fungus.

Sporulation degree: $+=0-10$ conidia/ microscopic field, $++=10-20$ conidia/ microscopic field, $+++=20-30$ conidia/ microscopic field, $++++=>30$ conidia/microscopic field.

From above results it is quite clear that potassium nitrate was most preferable nitrogen source for myceial growth and sporulation for pathogen Alternaria alternate (Fig. 2 and 3).

Table.1 Effect of different nitrogen sources on mycelial growth and sporulation of A. alternata

\begin{tabular}{|c|c|c|c|}
\hline Nitrogen source & Mean Colony Diameter $(\mathbf{c m})^{*}$ & Sporulation & Dry mass $(\mathbf{g})^{*}$ \\
\hline $\begin{array}{c}\text { Potassium } \\
\text { nitrate }\end{array}$ & 8.83 & & 2.11 \\
\hline Sodium nitrate & 6.72 & +++ & 2.01 \\
\hline Peptone & 4.00 & +++ & 1.59 \\
\hline Thiourea & 2.57 & + & 0.45 \\
\hline LSD $(\mathbf{P}=\mathbf{0 . 0 5})$ & $\mathbf{0 . 8 8}$ & & $\mathbf{0 . 2 3}$ \\
\hline
\end{tabular}

*Mean of three replications. 
Fig.1 Effect of different nitrogen source on radial growth and dry mass of A. alternata. Height of columns indicates the mean value of radial growth and dash line indicates the mean value of dry mass. The vertical bar indicates standard error (SE) of the mean.

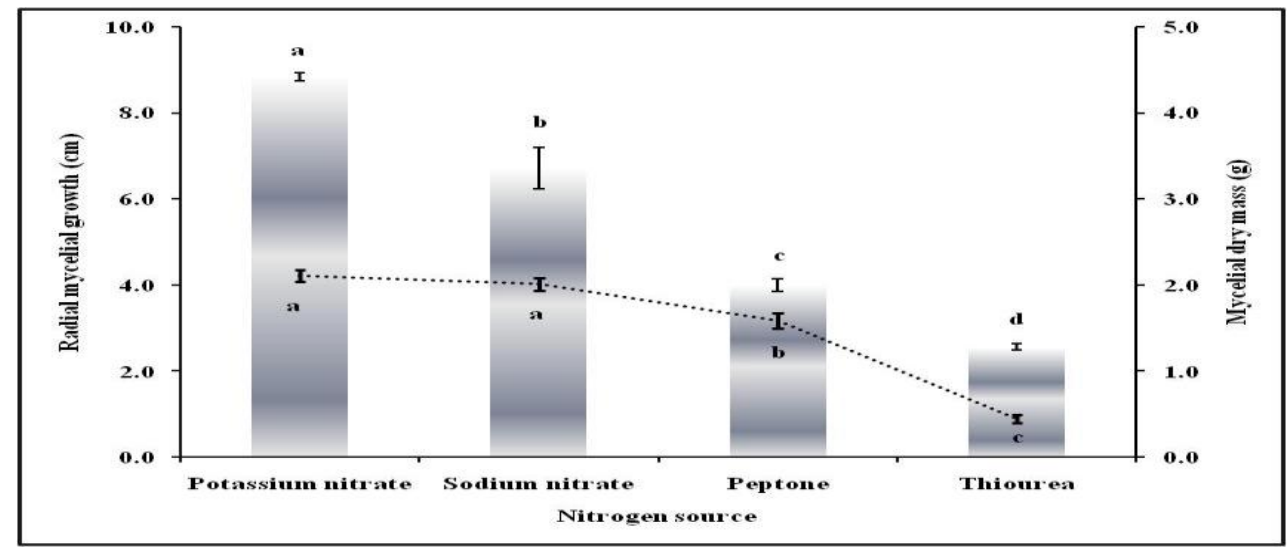

Fig.2 Effect of Nitrogen sources on radial growth of A.alternata

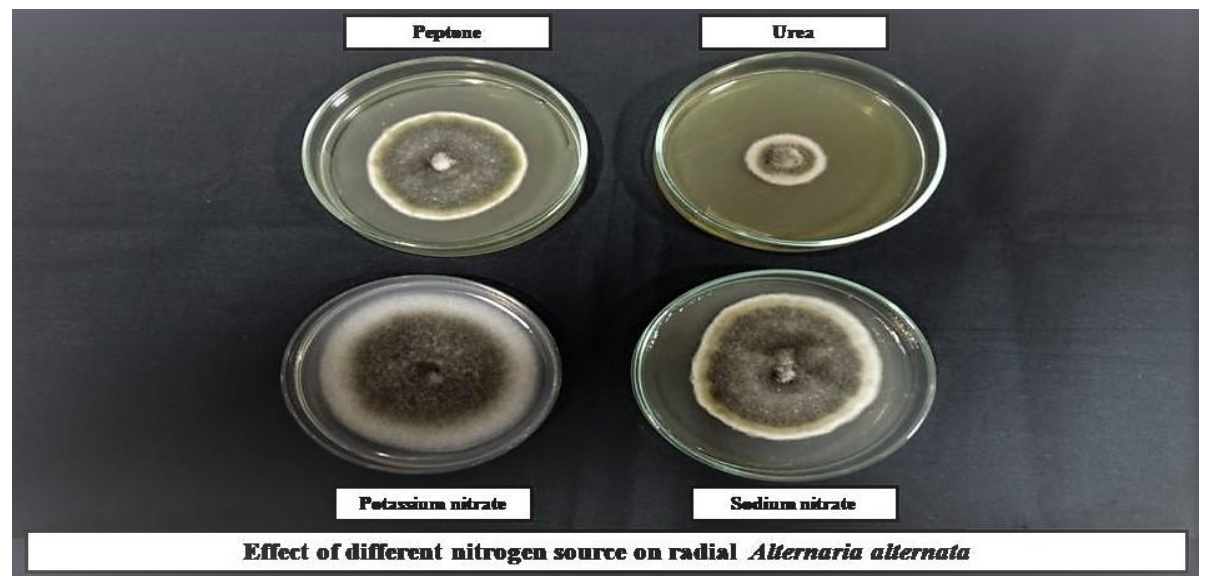

Fig.3 Effect of Nitrogen sources on dry mass of A.alternata

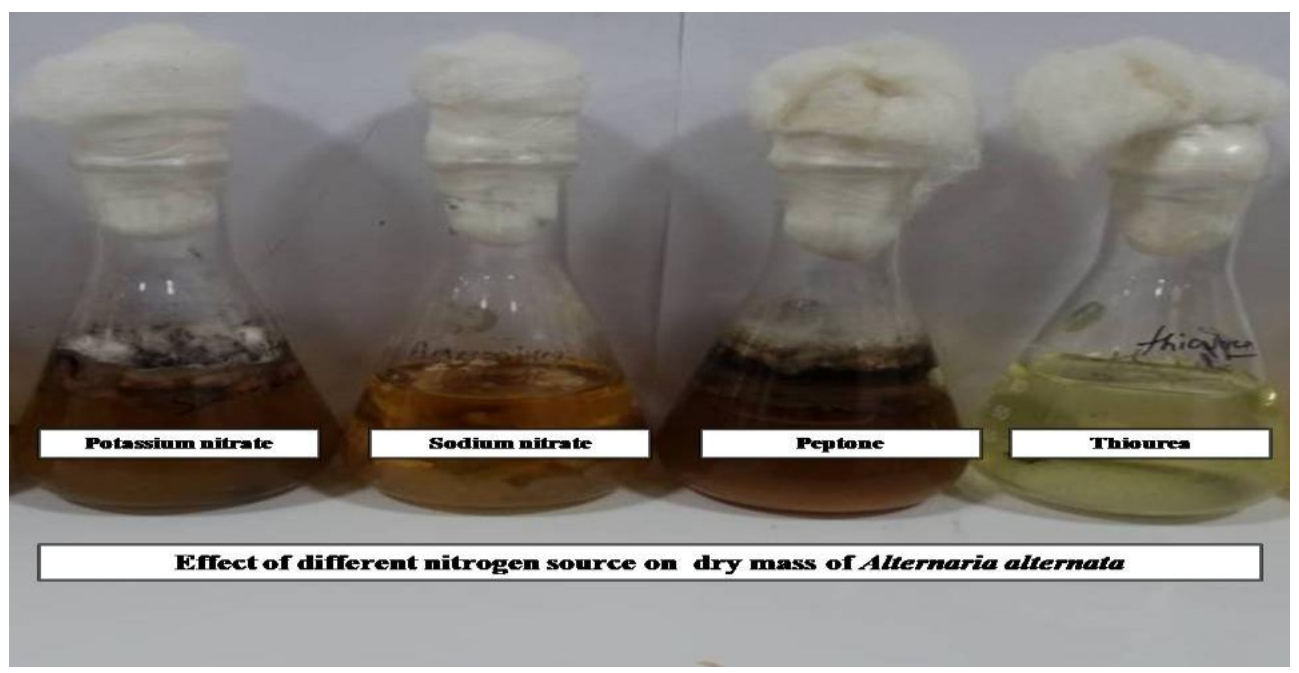




\section{Acknowledgment}

Authors are grateful to the Director, ICARNational Research Centre on Litchi, Muzaffarpur, Bihar, India for providing research facilities and necessary support to conduct this study.

\section{References}

Anal A.K.D, Kumar V and Varma A. 2019. Prevalence of leaf blight disease of litchi caused by Alternaria alternata in Bihar state, India. Eco. Env. \& Cons. 25 (4): 1789-1792

Cochrane, V.W. 1958. Physiology of the Fungi. John Wiley and Sons Inc., New York, Pages: 524.

Kumar V and Anal A.K.D. 2018. Incidence and severity of leaf, panicle and fruit blights of litchi caused by Alternaria alternata. Indian Phytopath. 71(1):153-157

Kumar V, Anal A.K.D, Rai S and Nath V.
2018. Leaf, panicle and fruit blight of litchi (Litchi chinensis) caused by Alternaria alternata in Bihar state, India. Can J Plant Pathol 40(1):84-89

Ramjegathesh R. and Ebenezar E.G. 2012. Morphological and Physiological Characters of Alternaria alternate Causing Leaf Blight Disease of Onion. Int. J. Plant Pathol. 3: 34-44.

Taware M.R, Gholve V.M, Wagh S.S, Kuldhar D.P, Pawar D.V and Chavan A.A. 2014. Effect of different culture media, temperature, $\mathrm{pH}$, carbon and nitrogen sources on mycelial growth and sporulation of Alternaria carthami causing Alternaria blight of safflower. Internat. J. Plant Protec. 7(2): 349353.

Vibha and Sinha, A. 2005. Production of Soluble Crude ProteinUsing Cellulolytic Fungi on rice stubble as substrate under wasteprogram management. Mycobiology. 33(3): 147-149.

\section{How to cite this article:}

Ajit Kumar Dubedi Anal, Ajit Varma, Vinod Kumar, Shalini Rai and Anil Chandra. 2021. Effect of Nitrogen Sources on Growth and Sporulation of Alternaria alternata causing Blight Disease in Litchi. Int.J.Curr.Microbiol.App.Sci. 10(02): 3395-3399.

doi: https://doi.org/10.20546/ijcmas.2021.1002.374 